\title{
Ilıman-Nemli İklim Bölgelerinde Kentsel Alanlarda Biyoklimatik Konfor
}

\author{
Aybüke Özge Boz Demir ${ }^{1 *}$, Canan Cengiz ${ }^{2}$ \\ 1* Bartın Üniversitesi, Mühendislik, Mimarlık ve Tasarım Fakültesi, Peyzaj Mimarlığı Bölümü, Bartın, Türkiye (ORCID: 0000-0003-2923-0590), aboz@,bartin.edu.tr \\ ${ }^{2}$ Bartın Üniversitesi, Mühendislik, Mimarlık ve Tasarım Fakültesi, Peyzaj Mimarlığı Bölümü, Bartın, Türkiye (ORCID: 0000-0003-1492-1081), \\ canancengiz@,bartin.edu.tr
}

(International Conference on Design, Research and Development (RDCONF) 2021 - 15-18 December 2021)

(DOI: 10.31590/ejosat.1045518)

ATIF/REFERENCE: Boz Demir, A. Ö. \& Cengiz, C. (2021). Ilıman-Nemli İklim Bölgelerinde Kentsel Alanlarda Biyoklimatik Konfor. Avrupa Bilim ve Teknoloji Dergisi, (32), 1134-1139.

$\ddot{O} \mathbf{z}$

Günümüzde yoğun ve plansız kentleşme, geçirimsiz yüzeylerin fazlalığı ve yeşil alan miktarının az olması sebebiyle kentler 1sınmakta ve kentsel 1Sı adaları oluşmaktadır. Kentsel 1Sı adalarının etkilerinin azaltılması için kentsel mikro iklimin iyileștirilmesi ve bu kapsamda başta yeşil alan miktarının artırılması olmak üzere çeşitli önlemler alınması önem taşımaktadır. COVID-19 küresel salgın döneminde yeşil alanlar başta olmak üzere kentsel kamusal alanların önemi daha da anlaşılmıştır. Dış mekânda doğa ile iletişim olanăğ sağlayan bu alanlar iklim özelliklerinden direkt etkilenmektedir. Bu kapsamda çalışmada, iklim ve insan ilişkisi, biyoklimatik konfor kavramı ve insan biyoklimatik konforunu etkileyen faktörler incelenmiş, ılıman-nemli iklim bölgelerinde biyoklimatik konforun sağlanmasının planlama ve tasarım açısından önemi ortaya koyulmuştur.

Anahtar Kelimeler: Küresel ısınma, İnsan biyoklimatik konforu, Ilıman-nemli iklim, Kentsel peyzaj planlama ve tasarım

\section{Bioclimatic Comfort at Urban Areas in Temperate-Humid Climate Regions}

\begin{abstract}
Nowadays, cities warm up and urban heat islands form due to intensive and unplanned urbanization, large number of impermeable surfaces and the lack of green areas. It is important to take certain precautions such as increasing the green areas for enhancing the urban microclimate in order to decrease the impacts of urban heat islands. The importance of urban public spaces and predominantly those of green areas has been understood much better during the global COVID-19 pandemic period. These areas that enable interaction with nature in outdoor areas are directly affected from climate factors. In this scope, factors that have an impact on the human bioclimatic comfort along with the concept of bioclimatic comfort as well as the climate and human relationship have been examined in the present study thus putting forth the importance of attaining bioclimatic comfort in temperate-humid climate regions for planning and design.
\end{abstract}

Keywords: Global warming, Human bioclimatic comfort, Temperate-humid climate, Urban landscape planning and design.

*Sorumlu Yazar: aboz@bartin.edu.tr 


\section{Giriş}

Kentlerde yeşil alanların tahrip edilmesi, geçirimli yüzeylerin yerini asfalt ve betonla kaplanmış geçirimsiz yüzeylerin alması, fazla enerji tüketimi ve büyük/yüksek kentsel yapıların artması nedeniyle kentteki sıcaklık yükselmekte ve kentleşmenin en belirgin iklimsel göstergesi olan kentsel 1s1 adaları oluşmaktadır (Ekinci, 2016; Yüksel, 2005). Kentsel 1s1 adaları; çevrelerindeki kırsal ve yarı kırsal alanlardan daha yüksek sıcaklığa sahip kentleşmiş alanlardır (United States Environmental Protection Agency). Is1 adalar1 insanlarda psikoloijk ve fiziksel sağlık sorunlarına, fazla enerji tüketimine ve kirlilik miktarının artmasına neden olarak kentler için büyük sorunlar meydana getirmektedir (Nakata ve de Souza, 2013).

Yüksel (2005), kentin büyüklüğü, nüfusu, yüzey malzemelerinin termal özellikleri, vejetasyon eksikliği ve su geçirimsiz yüzeylerin artması nedeni ile evapotranspirasyon yoluyla olan 1sı kayıplarının azalması, koridor etkisi, rüzgâr hızının azalması, kirlilik ve antropojenik 1sı oluşumunun kentsel 1Sı adası oluşumunda rol oynadığını belirtmiştir.

Rizwan vd. (2008)'ne göre kentsel 1sı adası oluşumunda kontrol edilebilir ve kontrol edilemez faktörler etkilidir. Hava koşulları, rüzgâr hızı, antisiklon koşulları ve bulutluluk oranı kontrol edilemez doğal faktörlerdir. Kontrol edilebilir faktörler ise nüfus (antropojenik 1s1, hava kirleticiler) ve kentsel tasarım ve yapı (yeşil alan miktarı, yapı ve yüzey malzemeleri, gökyüzü görüş faktörü) ile ilgili olmak üzere iki ana bileşene bağlıdır.

Kuşçu Şimşek ve Şengezer (2012), kentsel 1S1 adası oluşumunu etkileyen faktörleri, kentsel fonksiyonlar (konut, sanayi, ticaret, yeşil alan ve ulaşım), kentsel özellikler (malzeme/albedo, geometri, yoğunluk, doku ve nüfus), sera gazları (enerji tüketimi, hava kirliliği, fosil yakıtların kullanımı) ve hava akışı (rüzgâr hızı ve yönü) olarak dört ana başlıkta toplamıştır.

Karaca (2019), kentsel ısı adası oluşumunda etkili faktörleri kentin büyüklüğü ve nüfus yoğunluğu, hava kirliliği, antropojenik 1S1, kentteki bitki örtüsünün azalmas1, kent geometrisi, kentsel yüzey malzemeleri olarak belirtmiştir. Bu faktörlerin neden olduğu kentsel 1s1 adalarının yoğunluğunun artması sonucu kentlerin içinde çevrelerindeki alanlara göre farklı iklim özelliklerine sahip mikro iklim alanları oluşmaktadır (Balık ve Yüksel, 2014).

Kentlerde sürdürülebilirliğin sağlanmasında kentsel 1sı adası etkisinin azaltılması önem taşımaktadır. Isı adası etkisinin azaltılması kentsel mikro iklimin iyileştirilmesi ile sağlanmaktadır (Gaitani vd., 2011).

Kentsel 1S1 adası etkilerini azaltmak için kentlerde çeşitli stratejiler uygulanmaktadır. Bu kapsamda kentlerde geliştirilen beş temel stratejiyi Amerika Birleşik Devletleri Çevre Koruma Ajans1 (United States Environmental Protection Agency-EPA), ağaç ve bitki örtüsünü artırmak, yeşil çatılar oluşturmak, serin (yansıtıcı) çatılar oluşturmak, yansıtıcı veya geçirgen kaldırımlar kullanmak ve akıllı büyüme uygulamalarını kullanmak olarak belirtmiştir (Tablo 1) (United States Environmental Protection Agency, t.y.). Kuşçu Şimşek (2013), kentsel 1sı adalarının azaltılmasına yönelik çözüm önerileri kapsamında kentlerdeki mevcut yeşil alan oranının artırılması, yeşil altyap1 uygulamalarının kullanılması, yapı ve yüzey malzemelerinin serin/yansıtıcı özellik taşıması, bina yönü ve yerleşimlerin iklim verileri ile uyumlu yapılması, antropojenik 1s1 salınımının azaltılması, enerji etkin planlama ve tasarımların yapılması, karbon emisyonlarının azaltılması ve kentsel hava koridorlarının oluşturulması gerektiğini belirtmiştir.

Tablo 1. Kentsel isı adalarının azaltılmasındaki stratejiler ve faydaları (United States Environmental Protection Agency'den tablolaştırılarak, t.y.)

\begin{tabular}{|c|c|}
\hline Strateji & Faydalar \\
\hline $\begin{array}{l}\text { Ağaç ve bitki örtüsünü } \\
\text { artırmak }\end{array}$ & \multirow{5}{*}{$\begin{array}{l}\text { - Enerji kullanımını azaltmak } \\
\text { - Hava kirliliğini azaltmak } \\
\text { - Hava kalitesini artırmak } \\
\text { - Sera gazı emisyonları } \\
\text { üretimini azaltılmak } \\
\text { - Yağmur suyu yönetimi } \\
\text { - Su kalitesini iyileştirmek } \\
\text { - İnsan sağlığı ve konforunu } \\
\text { artırmak } \\
\text { - Yaşam kalitesini } \\
\text { iyileştirmek }\end{array}$} \\
\hline Yeşil çatılar oluşturmak & \\
\hline $\begin{array}{l}\text { Serin (yansıtıcı) çatılar } \\
\text { oluşturmak }\end{array}$ & \\
\hline $\begin{array}{l}\text { Yansıtıcı veya geçirgen } \\
\text { kaldırımlar kullanmak }\end{array}$ & \\
\hline $\begin{array}{l}\text { Akıllı büyüme } \\
\text { uygulamalarını kullanmak }\end{array}$ & \\
\hline
\end{tabular}

İyileştirilmiş mikro iklim koşullarının kentlerin gelişimi için önemli etkileri vardır (Nikolopoulou vd., 2001). Mikro iklim, dış mekânların kalitesini belirleyen önemli bir faktördür ve kentsel çevrede dış mekân kullanımı için kritik bir parametredir (Chen ve Ng, 2012; Nikolopoulou ve Lykoudis, 2006). Dış mekân kullanıcıları, güneş ve gölge değişimleri, rüzgâr hızındaki değişiklikler, nem oranındaki değişiklikler ve diğer özellikler açısından doğrudan çevrelerinin etkisi altındadır. $\mathrm{Bu}$ nedenle insan termal konforu yerel mikro iklimden etkilenmektedir (Chen ve Ng, 2012).

Brownd ve Gillespie (1995), rüzgâr, hava sıcaklığı, nem gibi mikro iklim ögelerinin insan biyoklimatik konforu üzerindeki etkilerinin ve peyzaj ögelerinin mikro iklim üzerindeki etkilerinin anlaşılmasıyla termal konfora sahip yaşam alanlarının oluşturulabileceğini belirtmiştir.

D1ş mekânlarda mikro iklimi etkileyen faktörlerin ve termal konforun daha iyi anlaşılması, kentsel alan kalitesini artırmakta ve insan yaşam kalitesinin iyileştirilmesinde rol oynamaktadır. Aynı zamanda ekonomik açıdan da kente olumlu katkılar sunmaktadir (Erell vd., 2011; Lau ve Choi, 2021; Nikolopoulou vd., 2001).

Çalışmada iklim ve insan ilişkisi, biyoklimatik konfor kavramı ve insan biyoklimatik konforunu etkileyen faktörler incelenmiştir. $\mathrm{Bu}$ kapsamda 1lıman-nemli $1 \mathrm{klim}$ bölgelerinde biyoklimatik konforun sağlanmasının planlama ve tasarım açısından önemi ortaya koyulmuştur.

\section{2. İklim ve İnsan İlişkisi}

İklim, insan fizyolojisini doğrudan etkilemektedir. Eğer iklim elemanları ortamda aşırı derecede artarsa veya azalırsa insan sağlığı için olumsuz sonuçlar yaratabilir (Akman, 2014; Çalışkan, 2012). Baş ağrısı, bulantı, yorgunluk ve kramp gibi ısıya bağlı olarak gelişen semptomlar çalışma performansını da azaltmaktadir (Vanos, 2010). 
Planlama ve iklimin ortak kesişim noktasında insan bulunmaktadır. Bu kapsamda insan yaşam kalitesi açısından dikkat edilmesi gereken ve sıcaklık, nem, yağış, rüzgâr vb. iklim parametrelerine bağlı olan biyoklimatik konfor durumu planlama için önem teşkil etmektedir (Topay, 2007). Eski yerleşimler incelendiğinde insanların iklimle uyumlu yaşamı benimseyerek, yaşam biçimlerini iklime göre şekillendirdiği görülmektedir.

Eski Mısır, Sümer, Asur, eski Roma ve İspanya İslam kentlerinde iç ve dış mekân planlama ve tasarımlarında iklim koşulları önemli bir kriter olmuştur. İklimle uyumlu tasarım kapsamında meydan, bahçe ve avlularda su ve bitki kullanımı, binalarda yüksek ve sağır duvarlar, güneşin aşırı sıcaklığından korunmak için dar ve eğri sokaklar, gölgeli ve hava akımlı sirkülasyon ağları oluşturulmuştur (Altunkasa, 1987).

Ilıman iklimlerde evler, kalın duvarlı, pencereler kışın güneş ışı̆̆ını maksimum derecede alabilecek, yazın ise 1sı fazlasını dışarı verebilecek şekilde tasarlanmıştır. Sıcak iklimlerde evler, az duvar ve bölmeden oluşan hava sirkülasyonunun sağlandığı sürekli serin olacak şekilde tasarlanmış, 1s1 yansımasının sağlanabilmesi için beyaza boyanmıştır. Tüm yıl boyunca bol yağış ve sıcaklığa sahip olan tropikal iklimlerde ise sel baskınlarından korunmak için evler sırıklar üzerine inşaa edilmiş, çatılar suyun kolay akışını sağlamak amacıyla dik yapılmıştır (Watt ve Wilson, 1999).

Kentlerin planlanmasında bölgesel olarak iklim özellikleri, kentsel çevre koşulları ve kullanıcıların dış mekândaki termal konfor gereksinimleri dikkat edilmesi gereken hususlardır (Algeciras vd., 2016). Kentlerdeki açık alanların termal durumu, kullanıcıların bu alanlarda zamanlarının büyük bir kısmını geçirmesinden dolayı önem taşımakta ve alanı kullanma konusundaki kararlarını etkilemektedir (Balogun ve Daramola, 2019; Chen ve Ng, 2012).

\section{Biyoklimatik Konfor}

Biyoklimatik konfor kavramı ilk defa Olgyay (1973) tarafindan termal konfor olarak ortaya atılmış ve kullanılmıştır. Biyoklimatik konfor kavramı başlangıçta termal konfor kavramının mimari ve inşaat mühendisliği alanında yapılan çalışmalarda kullanılan hali olarak düşünülmüştür. Daha sonraki çalışmalarda termal konfor ve biyoklimatik konfor kavramları birbirinin yerine kullanılmıştır (Toy, 2010).

Biyoklimatik konfor, insanların bulundukları ortamın 1sıtılmasına veya soğutulmasına ihtiyaç olmaksızın rahat hissetme durumudur (Toy ve Yllmaz, 2009). Toy (2010), biyoklimatik konforu, kişilerin bulundukları çevrenin havasından olumsuz etkilenmeme ve yorgunluk hissetmeme durumu olarak tanımlamıştır. Çetin (2019) ise insanların rüzgâr, nem, sıcaklık ve yağış gibi iklim elemanlarına karşı enerji harcamadan kendilerini rahat hissettikleri ortamları biyoklimatik konfora sahip alanlar olarak belirtmiştir.

Biyoklimatik konforun saptanmasında önemli rol oynayan sıcaklık, nem, radyasyon ve rüzgâr durumunun yanısıra hava kirliliği ve bu kirliliğe bağlı olarak oluşan hastalıklar da insan konforunu etkilemektedir. Bu nedenle etkenler bir bütün olarak düşünülerek biyoklimatik konfor durumu saptanmalıdır (Topay ve Yilmaz, 2004).

İnsan biyoklimatik konforunu etkileyen faktörler iklim elemanlarından oluşan çevresel faktörler ve bireye ait özelliklerinden kaynaklanan kişisel faktörler olmak üzere iki ana başlık altında toplanabilir.

\section{Çevresel faktörler}

- Hava sicaklığı: Sicaklık, nicel değerleri içeren hava sıcaklığı ve algınan sicaklık olmak üzere iki unsurdan oluşmaktadır. Biyoklimatik konfor algısını, $36.5{ }^{\circ} \mathrm{C}$ olan ortalama insan vücut sıcaklığı ile $23{ }^{\circ} \mathrm{C}$ olan ortalama atmosfer sıcaklığı arasındaki etkileşim belirlemektedir. Bu sıcaklıklar arasında termal konfor dengedeyken insan vücudu bu sıcaklıkların dışında soğuğu veya teri algılamaktadır. Bu aralık değerleri dişında 1sıl konfor dengesi bozulmakta ve insan vücudu üşüme veya terlemeye başlamaktadır (Ünal Çilek, 2021a).

- Nispi nem: Nispi nem, hissedilen sıcaklık üzerinde rol oynamaktadır. Nispi nem hissedilen sıcaklığı artırarak biyoklimatik konfor durumunu olumsuz yönde etkilemektedir. Nisbi nem \%30'dan az ve \%90'dan fazla ise konfor şartları bozulmaya başlamaktadır (Çınar, 1999).

- Rüzgâr: Rüzgâr yönü ve hızı biyoklimatik konfor oluşturmada önemli etkiye sahiptir. Rüzgâr hızı insan vücudunda hissedilen sıcaklığı azaltmaktadır.

- Radyasyon: Radyasyon etkisi ile oluşan sıcaklık değeri "MRT" (Mean Radiant Temperature; ortalama yansıma sıcaklığı) olarak ifade edilmektedir. Diş mekânda radyasyon etkisi sonucu kişilerin giysileri üzerinde biriken 1sı cilde iletilerek insanı etkilediği için biyoklimatik konfor durumu açısından önem taşımaktadır (Toy, 2010).

\section{$>$ Kişisel faktörler}

- Metabolik sicaklık: İnsan vücudu, oksijeni ve besinler yoluyla aldığı enerjiyi kullanarak metabolik 1sı üretmektedir. İnsan vücudunun iç sıcaklığı belirli bir düzeyde olması gerektiğinden vücut sürekli olarak 1S1 üretmekte, bu 1S1 üretim miktarı dış mekân koşullarına göre değişmektedir. Vücut 1SıS1 çevre 1sısından düşükse vücutta 1sı üretimi yavaşlamakta, yüksekse ısı üretimi artmaktadır. Çevre ile vücut ısısının dengeli olduğu durumlar ise konforlu olarak kabul edilmektedir (Çağlak, 2021).

- Aktivite düzeyi: Metabolizmanın ürettiği 1s1, yapılan aktivite türü ve zorluk seviyesi ile bağlantılıdır (Çalışkan, 2013).

- Giysi faktörü: Biyoklimatik konforun sağlanmasında giysi faktörü, 1sı ve nem geçirgenlik özelliği açısından rol oynamakta, giysinin sarmalayıcı etkisi vücuttaki 1s1 ve nem dengesini korunmasına yardımcı olmaktadır (Marmaralı vd., 2006; Mirza, 2014). Giysi, çeşitli fiziksel aktiviteler ve farklı iklim elemanlarının etkisi altında ortalama vücut sıcaklığınının sağlanması için 1sı düzenleme sistemi oluşturmaktadır (Ünal Çilek, 2021a).

- Yaş ve cinsiyet: Metabolizma hızı yaş gruplarına bağlı olarak farklılık göstermektedir. Vücut 1sı dengesi bakımından çocuk (0-14 yaş) ve yaşlılar (65 yaş üstü), yetişkenlere göre daha hassastırlar. $\mathrm{Bu}$ durum çocuk ve yaşlıların biyoklimatik konfor aralıklarının daha dar olmasına neden olmaktadır. Aynı zamanda cinsiyet farklılığı da biyoklimatik konfor açısından önem taşımakta, kadınlar erkeklere göre daha sıcak hava koşullarını tercih etmektedir (Auliciems ve Szokolay, 2007).

- Boy ve kilo: İnsanların boy ve kiloları kan akışı, vücut yağ oranı ve vücut 1s1 transferi üzerinde etkilidir (Çelik ve Beyazıt, 2008). Vücut yă̆ oranı kişiye göre değişmekte olduğundan aynı ortamda bulunan kişilerin konfor değerlerinde de farklılık oluşmaktadır. 


\section{Ilıman-Nemli İklim Bölgelerinde Biyoklimatik Konforun Sağlanmasının Kentsel Peyzaj Planlama ve Tasarım Açısından Önemi}

Kentsel peyzaj planlama ve tasarım sürecinde doğal ve kültürel özellikler dikkate alınarak korunmakta, insanlar için de en elverişli yaşam standartları sağlanmaya çalışılmaktadır. Biyoklimatik konfor şartları da insanlar üzerinde etkili olduğundan planlama ve tasarımda önemli bir bileşen olarak yer almaktadır (Çetin ve Şevik, 2020). Ancak biyoklimatik konfor şartları çevresel ve kişisel faktörlerden etkilendiği için faktörlerin birinde meydana gelen değişiklik tüm sonuca etki edebilmektedir. $\mathrm{Bu}$ kapsamda bireye ait özelliklerinden kaynaklanan kişisel faktörlere müdahale edilememekteyken diş faktörler için çeşitli önlem ve düzenlemelerle iyileştirmeler yapilabilmektedir (Toy ve Y1lmaz, 2009).

Türkiye'nin iklim bölgeleri, çeşitli çalışma ve araştırmalarda farklı olarak sınıflandırılmaktadır. Kısa Ovalı (2009) yaptığı doktora çalışmasında, Türkiye iklim bölgelerini beş sınıf altında incelemiştir. Bunlar; sıcak-nemli, sıcak-kuru, 1lıman-nemli, 1lıman-kuru ve soğuk olmak üzere beş iklim bölgesidir. Çalışma kapsamında Kısa Ovalı (2009)'nın yaptığı sınıflandırmaya dayalı olarak ılıman-nemli iklim bölgelerinde biyoklimatik konforun sağlanması için planlama ve tasarım ölçütlerinden bahsedilmiştir.

Ilıman-nemli iklim bölgelerinde yazları 1lıman, kışlar serin karakterlidir, yağış ve nem miktarı yüksektir. İklim elemanlarından rüzgâr, iklim bölgelerinin özelliklerine göre istenen, korunan veya istenmeyen bir faktördür. Ilıman-nemli iklim bölgelerinde sıcak dönemde yüksek nem ve güneş 1şığından korunma, soğuk dönemde ise rüzgârdan korunma ve güneş 1şı̆̆ından yararlanma amaçlanarak tasarım yapılmalıdır. Cadde ve sokaklar soğuk dönemde rüzgârlardan korunacak, sıcak dönemde ise serin esintiden yararlanacak biçimde güneybatıya yönlenmeli, bu kapsamda yeşil dokunun yönlendirme işlevinden yararlanılmalıdır (Kısa Ovalı, 2009; Kisa Oval1, 2019).

İşlevsel ve konforu yüksek alanlar oluşturulmasında biyoklimatik konforun dikkate alınması gerekmektedir. $\mathrm{Bu}$ nedenle kentsel peyzaj planlama ve tasarım çalışmalarında alan seçimi önem taşımaktadır. Alan seçiminde biyoklimatik konfor bakımından uygun alanların belirlenmesi ve kullanımların bu bölgelerde oluşturulması hem konforlu mekân oluşumuna hem de kullanım potansiyeline önemli ölçüde katkı sağlayacaktır.

Doğal verilerin önemli bir parametresi olan iklim verileri kullanıcıların alanı tercih etmesinde, alanın hangi dönemlerde daha çok kullanılacağı konusunda, alanda yapılacak aktivite türü ve süresi üzerinde etkilidir (Toy ve Yılmaz, 2009). Bu bağlamda biyoklimatik konfor durumu açık-yeşil alanların kullanım durumlarını ve kalitesini, açık-yeşil alanlar ise kentlerde oluşturdukları mikroiklim etkisi ile aşırı sıcak ve soğuk ortamların oluşmasını önleyerek kentleri olumlu yönde etkilemektedir.

Bitkisel uygulamalarda sıcak ve soğuk dönemde termal konforun sağlanması amaçlanmalıdır. Yaprak döken bitki türleri yazın gölge oluşturmada kışın ise güneş 1şınlarını geçirerek 1sınma sağlamada etkildir (Korkut vd., 2017; Ünal Çilek, 2021b).
Farklı yüzeylerin güneş enerjisini yansıtma ve soğurma miktarları değişiklik göstermektedir. Açık renkli, parlak ve cilalı yüzeyler güneş 1şı̆̆ını yansıtarak soğurulan 1sı miktarının azalmasına, koyu renkli, mat ve pürüzlü yüzeyler (taş, tuğla ve beton vb.) ise güneş ışınlarını emerek ısının tutulmasına neden olmaktadır (Watt ve Wilson, 1999; Yüksel, 2005). Geçirgen olmayan malzemeler suyun emilimini kısitlayarak suyun kısa sürede buharlaşmasına neden olmaktadır. $\mathrm{Bu}$ durum su döngüsünü bozmakta, gün içerisindeki buharlaşma süresini azaltarak diş mekândaki hissedilen hava sıcaklığını artırmaktadır. Geçirgen malzeme kullanımı ise su döngüsü ve yüzey malzemelerinin soğumasını sağlayarak, ortamdaki hava sıcaklığının azaltılmasında etkilidir (Köseoğlu, 2012).

$\mathrm{Su}$ yüzeyleri diş mekân biyoklimatik konforunun sağlanmasında gelen ışınları yansıtma ve buharlaşma etkisi ile öne çıkmaktadır. Özellikle sıcak dönemlerde çevrenin serinletilmesini sağlamakta aynı zamanda insanlara görsel ve psikolojik olumlu katkılar sunmaktadır.

\section{Sonuç}

COVID-19 pandemisinin devam ettiği günümüzde, yeşil alanlar başta olmak üzere kentsel kamusal alanlar insanların doğa ile iletişim kurdukları değerli alanlar olarak karşımıza çıkmaktadır. $\mathrm{Bu}$ dış mekân kullanımları kent ekosistemine olumlu katkılar sunmakta, insanlara da psikolojik ve fiziksel açıdan fayda sağlamaktadır. Bu nedenle iklim elemanlarının doğrudan etkisi altında olan dış mekân kullanımlarının sıcak ve soğuk dönemde kullanımını sağlamak için insan biyoklimatik konforunun sağlanacağı planlama ve tasarımlar yapılmalıdır.

Ilıman-nemli iklim bölgelerinde sicak dönemde kentsel kamusal açık ve yeşil alanların kullanımında güneş 1şınlarına maruz kalan kullanıcılarda termal olarak rahatsız olma durumu ortaya çıkmaktadır. Hava sıcaklığı, nem ve yüzey sıcaklığ birleştiğinde kullanıcılarda sağlık sorunları ile alan kullanımlarında zorluk ve engellere neden olabilmektedir. Dış mekânda biyoklimatik konfor dengesi oluşturulduğunda ise bu durum tersine çevrilerek mekânın canlılığı artırılabilmektedir (Givoni vd., 2003). Özellikle 1lıman-nemli iklim bölgelerinde doğa ile iletişim olanağı sağlayan kentsel kamusal yeşil alanlarda iklim ve insan ilişkisine yönelik kullanıcı konforunun sağlanmasında kavramsal çerçeveyi oluşturan biyoklimatik konfor toplumsal sağlık, alan kullanım tercihi ve memnuniyetin sağlanmasının yanı sıra yaşam kalitesine olan etkileri ile iklimle uyumlu planlama ve tasarımda öncelikli konular arasında önem taşımaktadır.

\section{Kaynakça}

Akman, Y. (2011). Iklim ve biyoiklim. Ankara: Palme Yayınları. Algeciras, J. A. R., Coch, H., Pérez, G., Yeras, M. C., \& Matzarakis, A. (2016). Human thermal comfort conditions and urban planning in hot-humid climates-The case of Cuba. International journal of biometeorology, 60, 11511164.

Altunkasa M. F. (1987). Çukurova Bölgesi'nde biyoklimatik veriler kullanılarak açık ve yeşil alan sistemlerinin belirlenmesi üzerine bir araştırma. Doktora Tezi, Çukurova Üniversitesi Fen Bilimleri Enstitüsü, Adana.

Auliciems, A., \& Szokolay, S. V. (1997). Thermal Comfort, Design Tools and Techniques. Passive and Low Energy 
Architecture in association with Dept. of Architecture, University of Queensland.

Balık, H., \& Yüksel, Ü. D. (2014). Planlama sürecine iklim verilerinin entegrasyonu. Türk Bilimsel Derlemeler Dergisi, 7(2), 1-6.

Balogun, I. A., \& Daramola, M. T. (2019). The outdoor thermal comfort assessment of different urban configurations within Akure City, Nigeria. Urban Climate, 29, 1-13.

Brown, R. D., \& Gillespie, T. J. (1995). Microclimatic landscape design: Creating thermal comfort and energy efficiency. New York: John Wiley \& Sons.

Chen, L., \& Ng, E. (2012). Outdoor thermal comfort and outdoor activities: A review of research in the past decade. Cities, 29, 118-125.

Çağlak, S. (2021). İklim değişikliğinin biyoklimatik konfor şartlart üzerine etkileri ve olast sonuçlart. Doktora tezi, Ondokuz Mayıs Üniversitesi Lisansüstü Eğitim Enstitüsü, Samsun.

Çalışkan, O. (2012). Türkiye'nin biyoklimatik koşullarının analizi ve şehirleşmenin biyoklimatik koşullara etkisinin ankara ölçeğinde incelenmesi. Doktora Tezi, Ankara Üniversitesi Sosyal Bilimler Enstitüsü, Ankara.

Çelik, N., \& Bayazıt, Y. (2008). İnsan vücudunun modellenmesinde kişisel değişikliklerin Termo-Regülasyon üzerindeki etkileri. Isı Bilimi ve Tekniği Dergisi, 28(1), 1722.

Çetin, I. Z., \& Şevik, H. (2020). Investigation of the relationship between bioclimatic comfort and land use by using GIS and RS techniques in Trabzon. Environmental monitoring and assessment, 192, 1-14.

Çetin, M. (2019). The effect of urban planning on urban formations determining bioclimatic comfort area's effect using satellitia imagines on air quality: a case study of Bursa city. Air Quality, Atmosphere \& Health, 12, 1237-1249.

Çınar, İ. (1999). Fiziksel planlamada biyoklimatik veriler kullanarak biyokonforun oluşturulmasl üzerine Fethiye merkezi yerleşimi üzerinde araştırmalar. Yüksek Lisans Tezi, Ege Üniversitesi Fen Bilimleri Enstitüsü, İzmir.

Ekinci, B. (2016). Kentsel alanlarda oluşan ısl adası etkisinin kentsel tasarım yöntemleri ile azaltılmast: Aksaray meydanı örneği. Yüksek Lisans Tezi, İstanbul Üniversitesi Fen Bilimleri Enstitüsü, İstanbul.

Erell, E., Pearlmutter, D., \& Williamson, T. (2011). City weathers: Meteorology and urban design 1950-2020. University of Manchester, Manchester Architecture Research Centre.

Gaitani, N., Mihalakakou, G., \& Santamouris, M. (2007). On the use of bioclimatic architecture principles in order to improve thermal comfort conditions in outdoor spaces. Building and Environment, 42, 317-324.

Givoni, B., Noguchi, M., Saaroni, H., Pochter, O., Yaacov, Y., Feller, N., \& Becker, S. (2003). Outdoor comfort research issues. Energy and buildings, 35, 77-86.

Karaca, Ü. B. (2019). Kentsel 1S1 adası oluşumunda kentsel yüzeylerin etkileri. Aksoy, Y. (Ed.), İklim Değişikliği ve Kentler-Yapısal Çevre ve Yeşil Alanlar içinde (s. 495-510.). Dakam Yayınları.

Kısa Ovalı, P. (2009). Türkiye iklim bölgeleri bağlamında ekolojik tasarım ölçütleri sistematiğinin oluşturulmas "Kayaköy yerleşmesinde örneklenmesi”. Doktora Tezi, Trakya Üniversitesi Fen Bilimleri Enstitüsü, Edirne.
Kısa Ovalı, P. (2019). Biyoklimatik Tasarım Matrisi (Türkiye). Trakya University Journal of Engineering Sciences, 20(2), 51-66.

Korkut, A., Kiper, T., \& Üstün Topal, T. (2017). Kentsel peyzaj tasarımda ekolojik yaklaşımlar. Artium, 5(1), 14-26.

Köseoğlu, B. (2012). Kentsel kamusal mekânların iklim duyarlı tasarlanması: Türkiye örneklerinin karşılaştırılması. Yüksek Lisans Tezi, Gazi Üniversitesi Fen Bilimleri Enstitüsü, Ankara.

Kuşçu Şimşek, Ç. (2013). İstanbul'da kentsel iklim üzerine antropojenik etkiler: Kentsel 1sı adalarının incelenmesi. Doktora Tezi, Yıldız Teknik Üniversitesi Fen Bilimleri Enstitüsü, İstanbul.

Kuşçu Şimşek, Ç., \& Şengezer, B. (2012). İstanbul metropoliten alanında kentsel ısınmanın azaltılmasında yeşil alanların önemi. Megaron, 7(2), 116-128.

Lau, K. K., \& Choi, C. Y. (2021). The influence of perceived aesthetic and acoustic quality on outdoor thermal comfort in urban environment. Building and Environment, 206, 1-13.

Marmaralı, A., Dönmez Kretzschmar, S., Özdil, N., \& Gülsevin Oğlakcioğlu, N. (2006). Giysilerde 1sıl konforu etkileyen parametreler. Tekstil ve Konfeksiyon, 16(4), 241-246.

Mirza, E. (2014). Rekreasyonel planlama için biyoiklimsel konfor özelliklerinin belirlenmesi: Isparta kent merkezi örneği. Yüksek Lisans Tezi, Süleyman Demirel Üniversitesi Fen Bilimleri Enstitüsü, Isparta.

Nakata, C. M., \& de Souza, L.C.L. (2013). Verification of the influence of urban geometry on the nocturnal heat island intensity. Journal of Urban and Environmental Engineering, 7(2), 286-292.

Nikolopoulou, M., Baker, N., \& Steemers, K. (2001). Thermal comfort in outdoor urban spaces: Understanding the human parameter. Solar Energy, 70(3), 227-235.

Nikolopoulou, M., \& Lykoudis, S. (2006). Thermal comfort in outdoor urban spaces: Analysis across different European countries. Building and Environment, 41, 1455-1470.

Rizwan, A. M., Dennis, Y. C. L., \& Liu C. (2008). A review on the generation, determination and mitigation of urban heat island. Journal of Environmental Sciences, 20, 120-128.

Topay, M. (2007). The importance of climate for recreational planning of rural areas: Case study of Muğla Province, Turkey. In A. Matzarakis, C. R de Freitas, D. Scott (Eds.) Developments in Tourism Climatology (pp. 29-36).

Topay, M., \& Y1lmaz, B. (2004). Biyoklimatik konfora sahip alanların belirlenmesinde CBS'den yararlanma olanakları: Muğla İli örneği. 3. Coğrafi Bilgi Sistemleri Bilişim Günleri içinde (s. 1-12). İstanbul.

Toy, S. (2010). Biyoklimatik konfor değerleri bakımından doğu anadolu bölgesi rekreasyonel alanlarının incelenmesi. Doktora Tezi, Atatürk Üniversitesi Fen Bilimleri Enstitüsü, Erzurum.

Toy, S., \& Yılmaz, S. (2009). Peyzaj tasarımında biyoklimatik konfor ve yaşam mekanları için önemi. Atatürk Üniversitesi Ziraat Fakültesi Dergisi, 40, 133-139.

United States Environmental Protection Agency (t.y.). Heat Island Cooling Strategies. Erişim Adresi: https://www.epa.gov/heatislands Erişim Tarihi: 15.11.2021

Ünal Çilek, M. (2021a). Outdoor thermal comfort indicators and indices. In L.G. Kaya, F. Çelik Aslan (Eds). Academic Research and Reviews in Architecture, Planning and Design Sciences (pp. 19-40). İzmir: Duvar Publishing.

Ünal Çilek, M. (2021b). Kamusal yeşil alanlar ile ısıl konfor arasındaki ilişkilerin modellenmesi: Adana kenti örneği. 
Doktora Tezi, Çukurova Üniversitesi Fen Bilimleri Enstitüsü, Adana.

Vanos, J. K., Warland J. S., Gillespie T. J., \& Kenny N. A. (2010). Review of the physiology of human thermal comfort while exercising in urban landscapes and implications for bioclimatic design. International Journal of Biometeorology, 54, 319-334.

Watt, F., \& Wilson, F. (1999). Hava ve iklim. (G.B. Bağcı, Çev.). Ankara: Tübitak Yayınları.

Yüksel, Ü. (2005). Ankara kentinde kentsel ısl adasl etkisinin yaz aylarında uzaktan algilama ve meteorolojik gözlemlere dayalı olarak saptanması ve değerlendirilmesi üzerinde bir araştırma. Doktora Tezi, Ankara Üniversitesi Fen Bilimleri Enstitüsü, Ankara. 